\title{
Hyperspectral Survey Method to Detect the Titanium Dioxide Percentage in the Coatings Applied to the Cultural Heritage ${ }^{\dagger}$
}

\author{
Antonio Costanzo 1,*, Donatella Ebolese 2, Sergio Falcone ${ }^{1}$, Carmelo La Piana ${ }^{1}$, \\ Silvestro Antonio Ruffolo ${ }^{3}$, Mauro Francesco La Russa ${ }^{3}$ and Massimo Musacchio ${ }^{4}$ \\ 1 Istituto Nazionale di Geofisica e Vulcanologia, 87036 Rende (CS), Italy; sergio.falcone@ingv.it (S.F.); \\ carmelo.lapiana@ingv.it (C.L.P.) \\ 2 Department of Culture and Society, University of Palermo, 90128 Palermo, Italy; \\ donatellaebolese@gmail.com \\ 3 Department of Biology, Ecology and Earth Sciences, University of Calabria, 87036 Rende (CS), Italy; \\ silvestro.ruffolo@unical.it (S.A.R.); mauro.larussa@unical.it (M.F.L.R.) \\ 4 Istituto Nazionale di Geofisica e Vulcanologia, 00143 Rome, Italy; massimo.musacchio@ingv.it \\ * Correspondence: antonio.costanzo@ingv.it; Tel.: +39-0984-496068 \\ + Presented at the 4th International Electronic Conference on Sensors and Applications, 15-30 November \\ 2017; Available online: http://sciforum.net/conference/ecsa-4.
}

Published: 14 November 2017

\begin{abstract}
Nanotechnologies provide new materials for the consolidation and protection of the Cultural Heritage: innovative solutions are represented by ethyl silicate or silica nanoparticles dispersed in aqueous colloidal suspensions mixed to titanium dioxide in nanometric form. The challenge of this work is to provide a quick and non-invasive survey method able to evaluate the titanium dioxide amount in the coatings applied on the treated stones. In fact, the titanium dioxide weight percentage incorporate into the coating depends on both application phase and, over time, environmental biological and chemical conditions. In this paper, we show the preliminary results obtained by spectroradiometric survey carried out on marble samples coated through nanoparticle films. The coatings were prepared increasing weight percentage of the titanium dioxide from $0 \mathrm{w} \%$ to $8 \mathrm{w} \%$. The data obtained through a field hyperspectral sensors shown spectral signatures depending on the content of titanium dioxide. In fact, the samples are characterized by different spectral shapes in the wavelength range $350-400 \mathrm{~nm}$, especially. The results are useful to develop a procedure for checking the application phase of coatings on the tangible Cultural Heritage. Moreover, the same method can be used, also, both to analyze the effect of the nanoparticle product on the base stone, before its application, and to verify the efficiency of the coating, over time.
\end{abstract}

Keywords: titanium dioxide; stone surfaces conservation; spectroradiometric sensor; hyperspectral material signatures; Cultural Heritage protection

\section{Introduction}

Nowadays, Heritage preservation activities provide for the interdisciplinary collaboration of several experts from scientific and humanistic field. The basic principles for a correct conservation treatment are to identify the problems, define the appropriate conservation actions and to select materials and procedures, taken into account some factors as the intrinsic stone properties, the degradation mechanisms and the environmental factors. Nanotechnologies provide new materials for the consolidation and protection of the Cultural Heritage: the implementation of innovative nanoproducts with a biocidal function, such as the titanium dioxide $\left(\mathrm{TiO}_{2}\right)$, in association with 
consolidant products and/or protective treatments, it is already a common practice for the treatment of the stone surfaces.

This nanomaterial provides important advantages in the conservation of cultural heritage and can be applied to traditional methods in order to strengthen the delicate and complex challenge of preservation. When particles have dimensions of about 1-100 nm, the materials properties change significantly. Nanomaterials have larger surface areas than similar masses of larger scale materials, which increase their chemical reactivity and present the possibility to penetrate deep into the damage stone materials stone materials [1].

In particular, atmospheric pollution is increasing the external degradation of monuments due the deposition of organic matter and other contaminants on the stone substrates. Nanometric $\mathrm{TiO}_{2}$ has become a promising photocatalytic material owing to its ability to catalyze the complete degradation of many organic contaminants and environmental toxins [2]. Innovative applications have reached by using $\mathrm{TiO}_{2}$ nanoparticles in stone materials such as environmental pollution remediation and anti-microbial effects, with regard to Cultural Heritage. In addition, $\mathrm{TiO}_{2}$ photoactive materials can also have water repellent properties which favor the self-cleaning action and prevent the generation of damage caused by water.

As a part of an integrated multi-analytical approach focused on the photocatalytic properties of titanium dioxide $\left(\mathrm{TiO}_{2}\right)$ such as a new environmentally friendly alternative for disinfection of stone materials, the paper presents a procedure to check the amount of $\mathrm{TiO}_{2}$ in the nanoparticle coatings by field hyperspectral surveys.

\section{Method}

\subsection{Sample Preparation}

In order to verify hydrophobic and biocidal features of $\mathrm{TiO}_{2}$-containing coatings, marble samples (a slab of $40 \times 20 \mathrm{~cm}$ and two samples of $5 \times 5 \mathrm{~cm}$ ) were treated with NANOESTEL ${ }^{\circledR}$ [3] and AEROXIDE ${ }^{\circledR} \mathrm{TiO}_{2} \mathrm{P} 25$ pure titanium dioxide [4].

NANOESTEL is a colloid system wherein the particles of $\mathrm{SiO}_{2}$ are dispersed in a water based solution. The dispersed nanoparticles have a diameter not higher than $20 \mathrm{~nm}$. Following the evaporation of water, particles link to each other and generate a silica gel able to build bridges between detached particles of stone (consolidation effect).

AEROXIDE $\mathrm{TiO}_{2} \mathrm{P}_{2} 5$ consists of aggregated primary particles (with a particles mean diameter of approximately $21 \mathrm{~nm}$ and aggregates of several hundred $\mathrm{nm}$ in size), with a high photoactivity hydrophilic character.

NANOESTEL was diluted to 3\% with deionized water and, successively, blended with different amounts of $\mathrm{TiO}_{2}$ (from $0 \mathrm{w} \%$ to $8 \mathrm{w} \%$ ). $\mathrm{TiO}_{2}$-containing coatings were applied on marble samples (Figure 1).

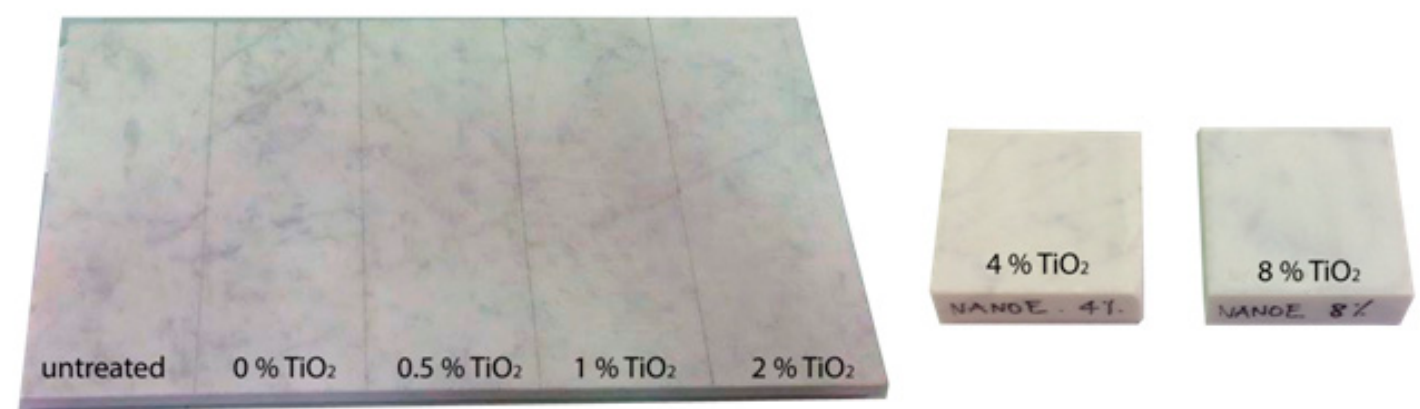

Figure 1. Marble samples covered by NANOESTEL, whit increasing weight percentage of titanium dioxide $\left(\mathrm{TiO}_{2}\right)$. For untreated material and $\mathrm{TiO}_{2}$ amount up to $2 \mathrm{w} \%$, the samples were obtained dividing into $40 \mathrm{~cm} \times 20 \mathrm{~cm}$ sections the same slab; whereas, for $4 \mathrm{w} \%$ and $8 \mathrm{w} \%$ other two samples of $5 \mathrm{~cm} \times 5 \mathrm{~cm}$ were prepared. 
Colorimetric measurement, methylene blue degradation test, accelerated aging tests through UV radiation and contact angle were carried out in order to evaluate the interaction between products and stone materials. With respect to untreated samples, these tests were undertaken to define some specific properties of the coating, such as chromatic variations, self-cleaning property, stability of the hydrophobic property of the film, effect on liquid water and variability of the contact angle.

\subsection{Spectral Signatures}

For the definition of the Spectral Signature, surface spectral measurements have been performed over 7 marble samples: 1 for untreated material, 1 coated with NANOESTEL and 5 with NANOESTEL blended with increasing $\mathrm{TiO}_{2}$ weight percentage $(0.5 \mathrm{w} \%, 1 \mathrm{w} \%, 2 \mathrm{w} \%, 4 \mathrm{w} \%$ and 8 $\mathrm{w} \%)$.

Measurements of solar reflected radiance were carried out with an analytical spectral device (ASD Inc., Longmont, Colorado, U.S.) FieldSpec pro portable spectroradiometer [5]. Three separate spectrometers cover the 350-2500 nm spectral range with 3 detectors: 1 in the VNIR (350-1000 nm) and 2 in the SWIR region (1001-1800 nm and 1801-2500 nm). These sensors are characterized by: spectral resolution of $3 \mathrm{~nm} @ 700 \mathrm{~nm}$ and $10 \mathrm{~nm} @ 1400 / 2100 \mathrm{~nm}$; spectral sampling of $1.4 \mathrm{~nm}$ and 1.1 $\mathrm{nm}$ in the ranges $350-1000 \mathrm{~nm}$ and $1001-2500 \mathrm{~nm}$, respectively; wavelength accuracy $0.5 \mathrm{~nm}$. All other technical specifications can be found in [5].

Measurements were carried out directly with the bare fiber-optic cable, which has a field of view of $25^{\circ}$ with. All samples have been acquired by following the same methodology. The fiber fore optic has been pointed toward the target with a same angular inclination of the solar incidence but in opposite direction. Moreover, the distance between fiber fore optic and target has been kept constant as much as possible. For each measurement 25 spectral signatures were collected. Furthermore, for each sample the 10 measurements were performed, in order to take into account variability of the local conditions due to the coating application and the base stone.

Measures of reflectance were collected on 31 March 2016. During the survey the weather was excellent and totally cloud free allowing the data collection over all different samples. For taking into account, also, the effect due to the environmental conditions, the measurements were repeated with the same procedures on 15 June 2016.

\section{Results and Discussion}

The Figure 2 shows the spectral signatures obtained by marble samples superficially covered by NANOESTEL coating, varying the $\mathrm{TiO}_{2}$ weight percentage. These measures are those collected on 15 June 2016. Note that the appreciable difference among the reflectance values are shown in the ultraviolet range (350-400 $\mathrm{nm}$ ) of the electromagnetic spectrum, especially. This behavior is strongly linked to the presence of titanium dioxide: in fact, its spectral signature available in the ASTER spectral library [6] allows to find very high slope already in the wavelength range from $400 \mathrm{~nm}$ to 410 $\mathrm{nm}$, with a strong decrease of reflectance moving towards the ultraviolet range.

The comparison among the spectral signatures increasing the $\mathrm{TiO}_{2}$ weight percentage (graph at the bottom right of Figure 2) shows relevant differences for $0.5 \mathrm{w} \%$ respect to the coating without titanium and a similar shape for amount greater than $4 \mathrm{w} \%$.

The comparison between the measures collected on the two different days show similar shapes of the normalized spectral signature: all reflectance values were divided by that at $400 \mathrm{~nm}$ wavelength for reducing the solar source effect. In particular, the Figure 3 shows a substantive similarity of the average spectral shapes up to wavelength of $410 \mathrm{~nm}$, even increasing the weight percentage of $\mathrm{TiO}_{2}$. 

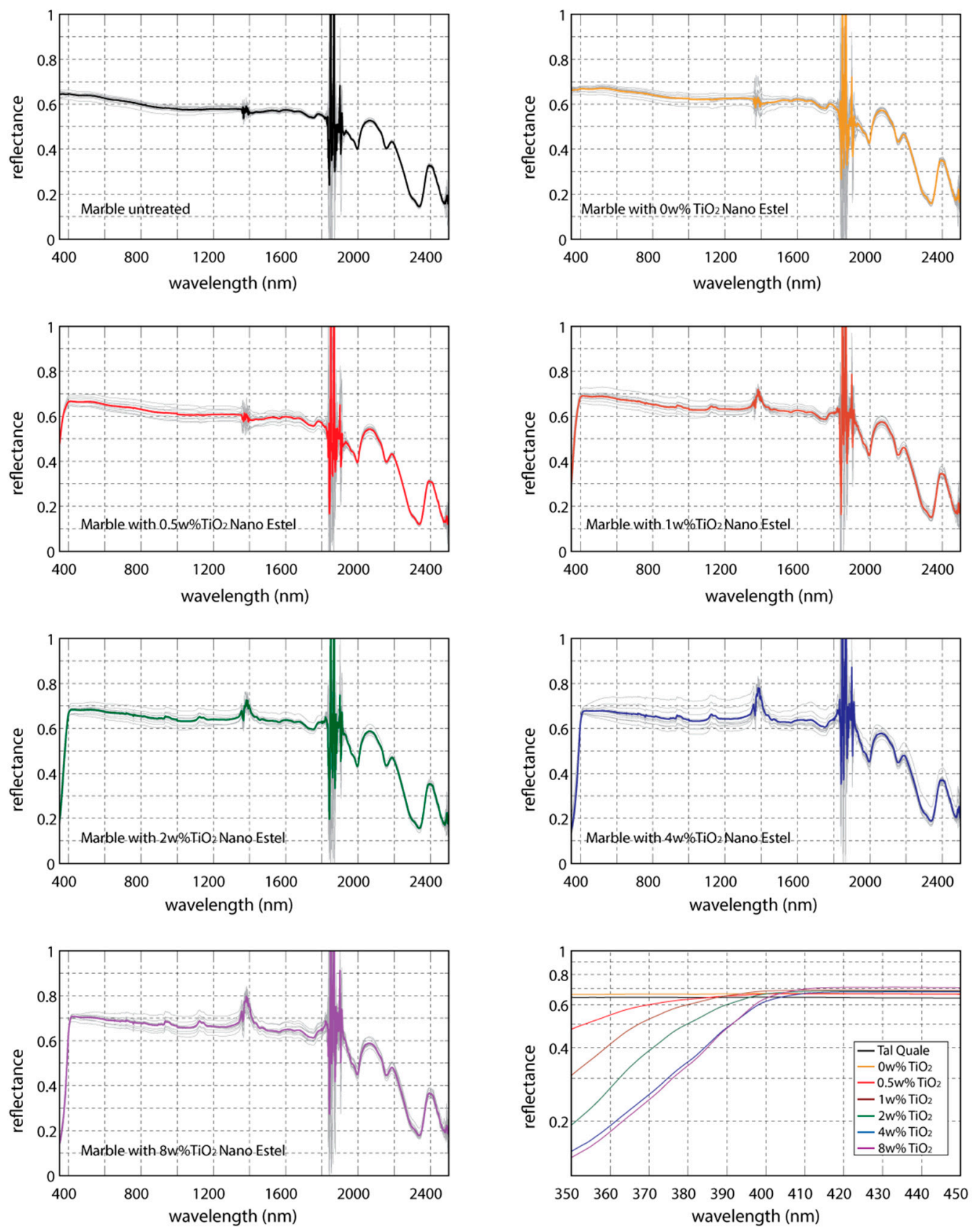

Figure 2. Spectral signatures obtained on marble samples covered by NANOESTEL, whit increasing weight percentage of titanium dioxide. Comparison among spectral signatures in the range 350-450 $\mathrm{nm}$ are shown in the bottom right panel. These measures were collected on 15 June 2016.
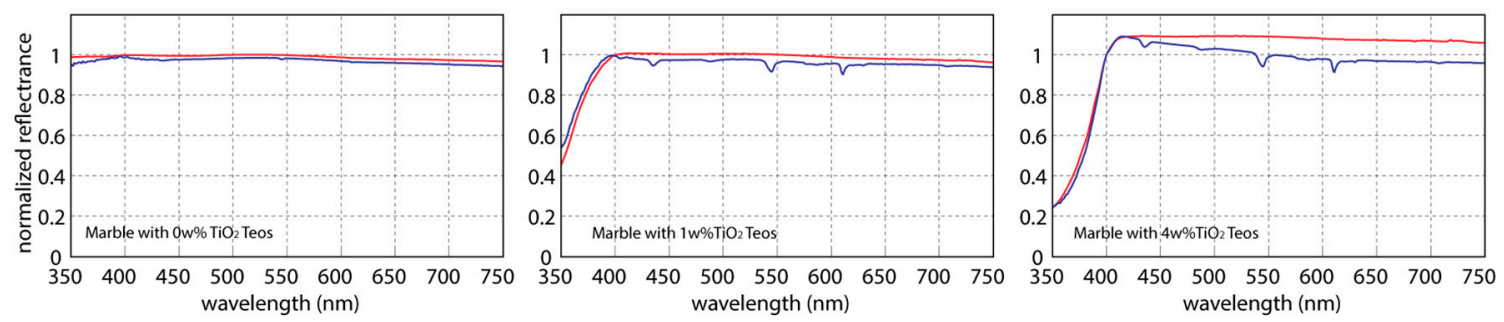

Figure 3. Comparison between average spectral signatures obtained by data collected on 31 March (blue lines) and 15 June (blue lines) 2016. For each signature, the reflectance values are normalized respect to that obtained at $400 \mathrm{~nm}$. 
To obtain a representative model, for each $\mathrm{TiO}_{2}$ weight percentage all data collected and normalized are interpolated through a quadratic polynomial with equation:

$$
R(w)=P_{1} \times w^{2}+P_{2} \times w+P_{3}
$$

In Equation (1): $R$ is reflectance normalized respect to that at wavelength of $400 \mathrm{~nm}, \mathrm{w}$ is the wavelength, $\mathrm{P}_{1}, \mathrm{P}_{2}$ and $\mathrm{P}_{3}$ are the coefficients.

Based on normalized reflectance data, in Figure 4 the fitting curves are reported for each $\mathrm{TiO}_{2} \mathrm{~W} \%$ analyzed. In the same figure, also, the 75th percentile confidence bounds are indicate in order to assess the statistical reliability of the models. The coefficients obtained by regression of data and RMSE (Root Mean Square Error) for assessing goodness of fits are reported in Table 1.
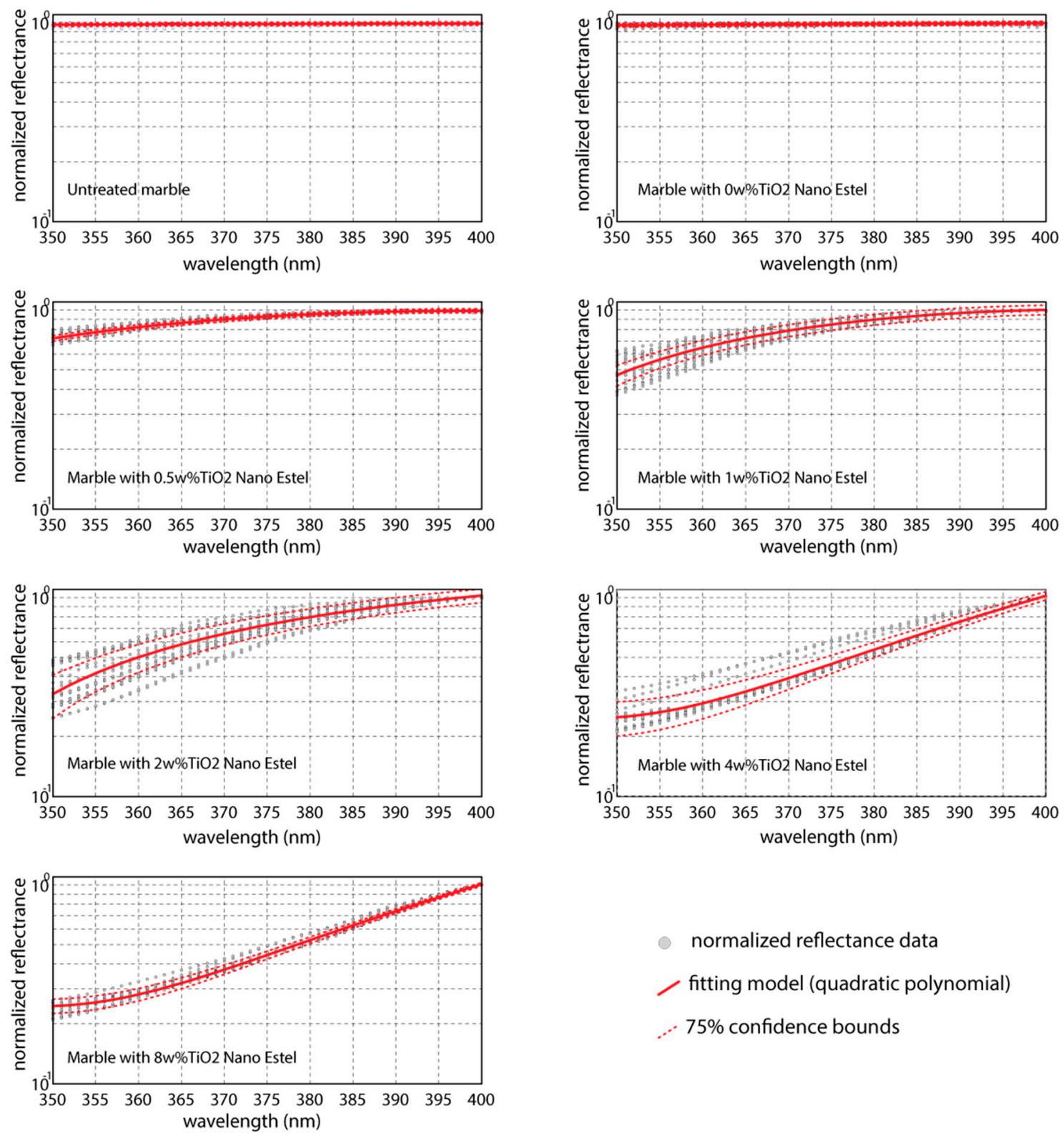

normalized reflectance data

fitting model (quadratic polynomial)

$\therefore 75 \%$ confidence bounds

Figure 4. Fitting curves obtained by data regression through quadratic polynomial functions. Data are reflectance values normalized respect to that at $400 \mathrm{~nm}$. 
Table 1. Parameters of the fitting models by quadratic polynomial functions.

\begin{tabular}{ccccc}
\hline TiO2 Weight Percentage & $\mathbf{P}_{1}{ }^{*}$ & $\mathbf{P}_{2}{ }^{*}$ & $\mathbf{P}_{3} *$ & RMSE \\
\hline Untreated & $-9.74 \times 10^{-4}$ & $4.00 \times 10^{-3}$ & $9.86 \times 10^{-1}$ & $1.77 \times 10^{-2}$ \\
$0 \mathrm{w} \%$ & $-1.07 \times 10^{-6}$ & $1.27 \times 10^{-3}$ & $6.57 \times 10^{-1}$ & $1.43 \times 10^{-2}$ \\
$0.5 \mathrm{w} \%$ & $-1.15 \times 10^{-4}$ & $9.16 \times 10^{-2}$ & $-1.73 \times 10^{1}$ & $2.02 \times 10^{-2}$ \\
$1 \mathrm{w} \%$ & $-1.75 \times 10^{-4}$ & $1.42 \times 10^{-1}$ & $-2.77 \times 10^{1}$ & $4.78 \times 10^{-2}$ \\
$2 \mathrm{w} \%$ & $-8.67 \times 10^{-5}$ & $7.90 \times 10^{-2}$ & $-1.67 \times 10^{1}$ & $6.99 \times 10^{-2}$ \\
$4 \mathrm{w} \%$ & $2.75 \times 10^{-4}$ & $-1.91 \times 10^{-1}$ & $3.34 \times 10^{1}$ & $4.21 \times 10^{-2}$ \\
$8 \mathrm{w} \%$ & $2.93 \times 10^{-4}$ & $-2.04 \times 10^{-1}$ & $3.59 \times 10^{1}$ & $1.76 \times 10^{-2}$ \\
\hline
\end{tabular}

* The parameters $\mathrm{P}_{1}, \mathrm{P}_{2}, \mathrm{P}_{3}$ are coefficients referred to the Equation (1).

The observation of graphs and the analysis of errors seem to indicate a great reliability for $\mathrm{TiO}_{2}$ weight percentages lower than $1 \%$ and higher than $4 \%$; although, for intermediate values of $\mathrm{TiO}_{2} \mathrm{w} \%$ a higher dispersion of the data is encountered, also in these cases good results are shown (R-squared $>0.897$ ). Moreover, curves for $\mathrm{TiO}_{2} 4 \mathrm{w} \%$ and $8 \mathrm{w} \%$ are not statistically different.

Based on the results, the control chart in Figure 5 was obtained from the fitting curves, in order to assess the $\mathrm{TiO}_{2} \mathrm{w} \%$ from field spectroradiometric survey in the range $350-400 \mathrm{~nm}$.

The procedure was applied on three samples (named A, B and C in Figure 5) with unknown percentage of titanium dioxide. The first comparisons between the values provided by preparation laboratory and those resulting from the proposed model seem to show promising results (cf. values reported in Table 2).

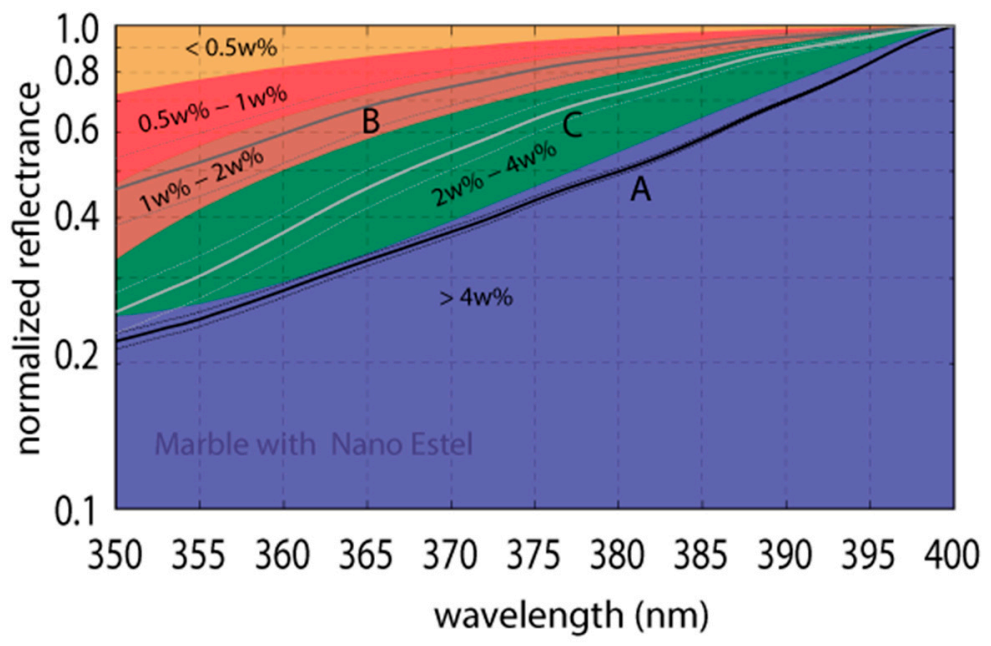

Figure 5. Control chart based on fitting curves (quadratic polynomials) reported in Figure 4. Curve for $\mathrm{TiO}_{2} 8 \mathrm{w} \%$ has been neglected, because it is not statistically different to $4 \mathrm{w} \%$ that, hence, only one area was identified with $\mathrm{TiO}_{2} \mathrm{w} \%>4 \%$.

Table 2. Comparison between $\mathrm{TiO}_{2}$ amounts provided by laboratory and valued through the control chart (cf. Figure 5) on three samples with unknown $\mathrm{TiO} 2$ weight percentage.

\begin{tabular}{ccc}
\hline Sample & $\mathrm{TiO}_{2} \mathbf{w} \%$ from Control Chart & $\mathrm{TiO}_{2} \mathbf{w} \%$ from Laboratory \\
\hline $\mathrm{A}$ & $>4 \mathrm{w} \%$ & $10 \mathrm{w} \%$ \\
$\mathrm{~B}$ & Included between $1 \mathrm{w} \%$ and $2 \mathrm{w} \%$ & $1 \mathrm{w} \%$ \\
$\mathrm{C}$ & Included between $2 \mathrm{w} \%$ and $4 \mathrm{w} \%$ & $4 \mathrm{w} \%$ \\
\hline
\end{tabular}

\section{Conclusions}

In this work, coatings with NANOESTEL, blended to different weight percentages of the $\mathrm{TiO}_{2}$, were applied on marble samples and tested through field spectroradiometric survey. The results were useful to develop a procedure both to check the application phase of the product on the Cultural Heritage and to control the coating state on the based stone, over time. 
In the data processing, simple quadratic polynomials were used to interpolate hyperspectral data, and to build a control chart able to provide a fast response about the $\mathrm{TiO}_{2}$ weight percentage by field surveys, directly. The study was focused on the data analysis in the 350-400 nm wavelength range, where the influence of titanium dioxide appears more evident, further analyses are under development to verify possible effects on other spectrum ranges.

Forthcoming developments in this study concern the compared analyses of field hyperspectral data obtained by marble and travertine stones coated with different nanoparticles products (NANOESTEL, TEOS, etc.). Furthermore, applications of the proposed procedure to artifacts and facades, directly exposed to weather, biological and chemical changes, will be evaluated.

Author Contributions: In this article: A.C. and D.E. wrote the manuscript and M.M., M.L.R. and S.A.R. attended in drafting; D.E., S.A.R. and M.F.L.R. participated in the preparation of the samples; A.C., supported by S.F. and C.L.P., performed the field hyperspectral survey; A.C., supported by M.M., conceived the procedure of the data analysis; All authors give final approval of the version submitted.

Conflicts of Interest: The authors declare no conflict of interest.

\section{References}

1. Sierra-Fernandez, A.; Gomez-Villalba, L.S. Rabanalb; M.E.; Fort, R. New nanomaterials for applications in conservation and restoration of stony materials: A review. Mater. Constr. 2017, 67, e107, doi:10.3989/mc.2017.07616.

2. La Russa, M.F.; Ruffolo, S.A.; Rovella, N.; Belfiore, C.M.; Palermo, A.M.; Maria, T.; Guzzi, A.M.; Gino, M.; Crisci, G.M. Multifunctional $\mathrm{TiO}_{2}$ coatings for Cultural Heritage. Prog. Org. Coat. 2012, 74, 186-191, doi:10.1016/j.porgcoat.2011.12.008.

3. CTS SRL, NANOESTEL®. Available online: http://www.ctseurope.com/en/scheda-prodotto.php?id=229 (accessed on 20 October 2017).

4. EVONIK's, AEROXIDE® $\mathrm{TiO}_{2} \quad \mathrm{P} 25 . \quad$ Available online: https://www.aerosil.com/lpaproductfinder/page/productsbytext/detail.html?pid=1822 (accessed on 20 October 2017).

5. ASD Inc. FieldSpec 4 Standard-Res Spectroradiometer. Available online: https://www.asdi.com/productsand-services/fieldspec-spectroradiometers/fieldspec-4-standard-res (accessed on 20 October 2017).

6. Baldridge, A.M.; Hook, S.J.; Grove, C.I.; Rivera, G. The ASTER spectral library version 2.0. Remote Sens. Environ. 2009, 113, 711-715, doi:10.1016/j.rse.2008.11.007.

(C) 2018 by the authors. Licensee MDPI, Basel, Switzerland. This article is an open access article distributed under the terms and conditions of the Creative Commons Attribution (CC BY) license (http://creativecommons.org/licenses/by/4.0/). 